\title{
Optimization of the MIG Arc Weld-Brazing Process on Titanium and Aluminum Lap-Joint Welds Using the Taguchi Method, Grey Relational Analysis and Fuzzy Logic
}

\author{
Hsuan-Liang Lin ( $\nabla$ alaniin@ms47.hinet.net ) \\ National Kaohsiung Normal University \\ You-Jiun Wang \\ National Kaohsiung Normal University
}

\section{Research Article}

Keywords: MIG welding, titanium, aluminum, Taguchi method, grey relational analysis, fuzzy logic

Posted Date: May 18th, 2021

DOI: https://doi.org/10.21203/rs.3.rs-443418/v1

License: (c) (1) This work is licensed under a Creative Commons Attribution 4.0 International License. Read Full License 
Optimization of the MIG arc weld-brazing process on titanium and aluminum lap-joint welds using the Taguchi method, grey relational analysis and fuzzy logic

\author{
Hsuan-Liang Lin ${ }^{* 1}$, You-Jiun Wang ${ }^{1}$ \\ ${ }^{1}$ Department of Industry Technology Education, National Kaohsiung \\ Normal University, Kaohsiung, Taiwan
}

Submitted to

The International Journal of Advanced Manufacturing Technology

19 April 2021

*Corresponding author: Hsuan-Liang Lin

The ORCID of corresponding author: 0000-0002-4882-6915

Email ID of corresponding author: alaniin@ms47.hinet.net 


\begin{abstract}
The dissimilar materials lap-joint of Ti-6Al-4V titanium (Ti) and 6061 aluminum (Al) alloys was achieved through a metal inert gas (MIG) arc weld-brazing process. The relationships between the major MIG arc weld-brazing parameters such as travel speed of MIG torch, MIG welding current, argon flow rate of MIG torch, wettability of weld bead and mechanical property of Ti/Al lap-joint specimens were investigated. A proposed approach that integrates the Taguchi method, grey relational analysis (GRA) and fuzzy logic was employed to obtain the optimal MIG arc weld-brazing parameters. The proposed approach was adopted to solve the MIG arc weld-brazing process with multiple quality characteristics (QCs). The experimental procedure of this study not only improves the wettability of weld bead, but also increases the tensile strength of Ti/Al lap-joint specimens. Confirmation experiments revealed that this study could efficiently optimize the MIG arc weld-brazing parameters, and the average tensile strength of Ti/Al lap-joint specimens could reaches $178 \mathrm{MPa}$. During the MIG weld-brazing, higher argon flow rate of the MIG torch that produces turbulence to the weld pool and brings outside air could create a high amount of porosity over the weld bead.
\end{abstract}

Keywords: MIG welding; titanium; aluminum; Taguchi method; grey relational analysis; fuzzy logic 


\section{Introduction}

In recent years, the most widely employed lightweight structural materials were aluminum $(\mathrm{Al})$, magnesium $(\mathrm{Mg})$ and titanium $(\mathrm{Ti})$ alloys [1]. Due to the high specific strength and corrosion resistance, the Ti alloys have been employed in the aerospace industries [2]. Al alloys with a density two-thirds that of Ti alloys and low cost were widely applied in automotive industry [3]. Due to weight reduction, materials cost and environmental impact, the compound structures of Ti/Al have a wide range of great applications [1-3]. However, the large difference physical and chemical properties between $\mathrm{Ti}$ and $\mathrm{Al}$ alloys, the joining of $\mathrm{Ti} / \mathrm{Al}$ alloys is challenging [4]. Because of the brittle intermetallic compounds (IMCs) on the surface of $\mathrm{Ti}$ alloys, the $\mathrm{Ti} / \mathrm{Al}$ specimens that produced by traditional fusion welding process acquire poor mechanical properties. Some novel weld-brazing techniques such as laser weld-brazing and arc weld-brazing have been developed to the dissimilar materials joint. These novel techniques could control the generation of IMC [5]. The morphology and thickness of the IMC layer between $\mathrm{Ti}$ and $\mathrm{Al}$ alloys critically influence the mechanical properties of specimens. In addition, a suitable wettability of the filler materials would be beneficial to the mechanical properties of the weld-brazing specimens [5-6]. Chen et al. [7] adopted a $\mathrm{CO}_{2}$ spot laser weld-brazing technology to join Ti/Al butt-welds. Experimental results revealed that the tensile strength of specimens produced by low-heat input is higher than that by the high-heat input. Under the condition of high-heat input range, the fracture occur in the interface between $\mathrm{Ti}$ and $\mathrm{Al}$ alloy during the tensile testing process. Under the condition of low-heat input range, the fracture occur in the fusion zone of weld bead, and the tensile strength of Ti/Al specimens is no significant change. Li et al. [5] demonstrated that a dual-spot laser could 
improve the wettability of filler materials that would be beneficial to improve the mechanical properties of $\mathrm{Ti} / \mathrm{Al}$ specimens. In addition, it revealed that the morphology and thickness of IMC layer was determined to the mechanical properties of Ti/Al specimens, and the highest tensile strength of $\mathrm{Ti} / \mathrm{Al}$ specimens that the thickness of IMC layer at the range of $0.45 \pm 0.15 \mu \mathrm{m}$.

In spite of the quality of dissimilar materials joints that produced by the laser weld-brazing process was very good, the arc weld-brazing technology gains more attention than the laser welding process. Due to the lower heat input and cost, the tungsten inert gas (TIG) arc weld-brazing technology that proposed a great potential to fabricate the Ti/Al joint was developed [8]. Wan et al. [2] showed that a dissimilar material joint of $5 \mathrm{~A} 06 \mathrm{Al}$ and aluminised Ti was successfully achieved through the TIG arc weld-brazing technology. Because of the aluminised coating, the wettability of liquid filler materials on the surface of $\mathrm{Ti}$ plate was improved obviously. The tensile strength of the Ti/Al joints was up to 216 MPa. Nandagopal et al. [9] demonstrated that the TIG arc weld-brazing technology was implemented that employed a closed chamber for the dissimilar material joint of $\mathrm{Ti} / \mathrm{Al}$ alloys. It proved that the presence of $\mathrm{Ti}$, $\mathrm{Al}$ and $\mathrm{Si}$ at the interface between $\mathrm{Ti}$ and $\mathrm{Al}$ alloys was formed due to the slower welding speed. The percentage contributions of each parameter for tensile strength were welding speed $52.88 \%$ and welding current $44.08 \%$. The maximum tensile strength of the Ti/Al specimens was $342.2 \mathrm{MPa}$ in the TIG arc weld-brazing process that using a closed chamber. Neither the TIG arc weld-brazing processes developed by Wan et al. [2] nor Nandagopal et al. [9] were beneficial to the practical application, these techniques were limited for the productivity. On the contrary, the metal inert gas (MIG) arc welding has proven suitable for automatic welding. Miao et al. [10] utilized a bypass-current MIG (BC-MIG) arc 
weld-brazing technology to the Ti/Al lap-joint specimens. Compared to conventional MIG arc welding process, the BC-MIG arc weld-brazing process decreased the heat input on the surface of Ti plate and improved the melting efficiency of $\mathrm{Al}$ filler materials. The wettability of $\mathrm{Al}$ filler materials on the surface of Ti plate was improved significantly by using this novel weld-brazing technology. The results of this study demonstrated that the average tensile-strength of Ti/Al lap-joint specimens could reaches $180 \mathrm{MPa}$, which approximately $91 \%$ of $6061 \mathrm{Al}$ alloy.

Based on the previous studies [5-10], the heat input during the weld-brazing process and the wettability of weld bead (e.g., wetting angle and wetting length) on the surface of $\mathrm{Ti}$ plate were the significant parameters that affect the tensile strength of the Ti/Al specimens. This study search to acquire the optimal MIG arc weld-brazing parameters during the experimental procedure that produced a lap-joint of Ti/Al alloys. The schematic of novel MIG arc weld-brazing process and sampling specimens are shown in Fig.1. The previous studies $[6,11]$ demonstrated that the process parameters affect heat input, mechanical properties of specimens and wettability of $\mathrm{Al}$ filler materials significantly during the weld-brazing process. Therefore, the optimal MIG arc weld-brazing parameters are not easily acquired by means of the traditional experimental design. A proposed approach that developed by the author [12] integrated the Taguchi method and grey relational analysis (GRA) to solve the problem of multiple quality characteristics (QCs) in a novel MIG arc welding process. It revealed that the proposed approach would be improve to the fusion area and penetration of specimens simultaneously. Therefore, the Taguchi method and GRA were integrated to solve the problem of multiple QCs such as mechanical properties and wettability of Ti/Al specimens in this study. Generally, the wettability and tensile strength of Ti/Al specimens that produced by the MIG arc 
weld-brazing process vary greatly. It is suitable to apply the fuzzy logic to predict the wettability and tensile strength of specimens that were affected by the MIG arc weld-brazing process. A previous study [13] developed a proposed approach that integrates the Taguchi method, GRA and fuzzy logic to optimize an activated MIG welding process. The fuzzy logic was employed to solve the problem that the weld bead geometry varies considerably. The proposed approach is relatively effective and improves the depth-to-width ratio and penetration of $\mathrm{Al}$ alloy butt-joint simultaneously. In brief, the fuzzy logic is favorable to develop the relationship between the MIG arc weld-brazing parameters and the quality performance of specimens (e.g., wetting angle and tensile strength of specimens). The proposed approach that integrates Taguchi method, GRA and fuzzy logic was used to obtain the optimal MIG arc weld-brazing parameters. The purpose of this study was to improve tensile strength and wetting angle of Ti/Al lap-joint specimens simultaneously under the

optimal MIG arc weld-brazing process conditions. Based on the microstructure of tensile testing specimens, the failure analysis of Ti/Al lap-joint that produced by using the MIG arc weld-brazing was investigated.

\section{Experiment and method}

\subsection{MIG arc weld-brazing parameters}

The base metals adopted in this novel MIG arc weld-brazing process were the Ti-6Al-4V and $6061 \mathrm{Al}$ alloy sheets that the dimension of 100 $\mathrm{mm} \times 60 \mathrm{~mm} \times 2 \mathrm{~mm}$ and $100 \mathrm{~mm} \times 60 \mathrm{~mm} \times 3 \mathrm{~mm}$, respectively. The $4043 \mathrm{Al}$ alloy filler wires with $1.6 \mathrm{~mm}$ diameter were used to produce $\mathrm{Ti} / \mathrm{Al}$ dissimilar materials lap-joint specimens. The chemical content of $\mathrm{Ti}, \mathrm{Al}$ alloys and 4043 filler wires are shown in Table1. In 
order to avoid the melting of $\mathrm{Ti}$ alloy, the filler wire of MIG torch was irradiated from the Al side with $1 \mathrm{~mm}$ offset distance before the MIG arc weld-brazing process. As shown in Fig.1a, a tube is made of stainless steel with $15 \mathrm{~mm}$ diameter that placed on the surface of Ti plate to supply argon gas in the fusion area between $\mathrm{Ti}$ and $\mathrm{Al}$ plate. Therefore, this study employed the double shielding gas of argon to prevent oxidation of the base metals and molten filler materials, and to improve the wettability of weld bead. The main parameters of the MIG arc welding-brazing process used in the screen experiment of this study were listed in Table 2. After the MIG arc welding-brazing process, the Ti/Al lap-joint specimens were machined into ASTM E8 standard tensile testing specimen and cross-sections of samples using a water jet cutting machine as shown in Fig.1b. Tensile strength of specimens was measured at a speed of 0.5 $\mathrm{mm} / \mathrm{min}$. The wetting angle of Ti/Al lap-joint specimens was measured using an optical microscope $(\mathrm{OM})$. Based on the results of screen experiment, the levels of main MIG weld-brazing parameters were set as shown in Table 3. After the confirmation experiment, the fracture surfaces of the lap-joints and microstructure of brazing zone on the $\mathrm{Ti}$ plate surface were investigated by the scanning electron microscope (SEM).

\subsection{Experiment using the Taguchi method}

As shown in Fig.1b, the N1 and N2 of each Ti/Al lap-joint that was chosen as a noise factor for the specimens of tensile strength testing. The L9 orthogonal array (OA) was employed and presents an experimental layout that include three control factors and a noise factor, as shown in 
Table 4. This study arranged four repetitions $\left(y_{1}, y_{2}, y_{3}\right.$ and $\left.y_{4}\right)$ for each trial to accomplish a robust design. Based on the literature review of this study, the failure load of tensile strength testing and wetting angle of Ti/Al lap-joints were chosen as the multiple QCs. The failure load of Ti/Al lap-joint specimens is belong to the larger-the-better (LTB) QC. The signal-to-noise ratio (SNR) that proposed by Dr. Taguchi is employed to consider the effect of the mean and variation of QC simultaneously. The LTB type SNR can be defined as the equation (1a) [14].

$$
S N R_{L T B}=\eta_{L T B}=-10 \log \left(\frac{1}{n} \sum_{i=1}^{n} \frac{1}{y_{i}^{2}}\right)
$$

where $n$ is the number of experimental tests of each trial, and $n=4$ because four repetitions for each trial of L9 OA. The $y_{i}$ is the failure load of each tensile strength testing specimen in this study. In additions, Mathieu et al. [6] demonstrated that the mechanical property is correlated to the weld bead geometry of dissimilar materials lap-joints. The wetting angle of weld bead seems to have a strong influence on the mechanical property of $\mathrm{Al} / \mathrm{steel}$ laser lap-joints. For the tensile strength of $\mathrm{Al} / \mathrm{steel}$ lap-joints, the wetting angle of weld bead between 27 and 30 were better than that between 43 and 71. Singh et al. [11] revealed that increasing the thickness of $\mathrm{Al}$ sheet and the wetting angle increasing simultaneously during the Al/steel lap weld-brazing process. Thicker Al alloy sheets aid faster heat dissipation and result in rapid cooling of molten filler and increased the wetting angle. Therefore, the wetting angle of the Ti/Al lap-joints in this study belong to the nominal-the-best (NTB) QC. The NTB type SNR can be defined as the equation (1b) [14].

$$
S N R_{N T B}=\eta_{N T B}=-10 \log \left((\bar{y}-m)^{2}+s^{2}\right)
$$

where $\bar{y}$ is the average wetting angle of each trial, the $s$ is standard 
deviation for the wetting angle of each trial, the $m$ is the target value of wetting angle that obtained from the screen experiment in this study.

\subsection{Apply the GRA and fuzzy logic}

Taguchi effectively applies the idea of orthogonal arrays (OA) and signal-to-noise ratios (SNR) to obtain an optimal control factor level combination with a parameter design method [14]. First, the SNR values were calculated via equation $1 \mathrm{a}$ and $1 \mathrm{~b}$ for evaluating the failure load and wetting angle of the Ti/Al lap-joint specimens, respectively. Based on the meanings of SNR in the Taguchi method, the larger of SNR values, the better performance of MIG arc weld-brazing specimens. After the SNR calculation, the grey relational analysis (GRA) was used to handle the multiple QCs during the MIG arc weld-brazing. First, the SNR values were normalized in the range between 0 and 1 by the grey relational generation. The experimental results were normalized for LTB QCs using the as the equation (2) [15].

$$
x_{i}(k)=\frac{\eta_{i}(k)-\min \eta_{i}(k)}{\max \eta_{i}(k)-\min \eta_{i}(k)}
$$

where $x_{i}(k)$ is the normalized value, the $\eta_{i}(k)$ is the original SNR value for the $k_{t h}$ responses in the $i_{t h}$ experiment, the $\min \eta_{i}(k)$ is minimum SNR value of $\eta_{i}(k)$, and the $\max \eta_{i}(k)$ is maximum SNR value of $\eta_{i}(k)$ experimental results. Then, the grey relational coefficient $\delta_{i}(k)$ is estimated to present the relationship between the perfect and real normalized experimental results. The $\delta_{i}(k)$ is calculated via the equation (3) [16]:

$$
\delta_{i}(k)=\frac{\Delta \min +\varsigma \Delta \max }{\Delta_{o i}(k)+\varsigma \Delta \max }
$$

where $\Delta_{o i}(k)=\left\|x_{o}(k)-x_{i}(k)\right\|$ and $x_{o}(k)$ present the ideal value 
that generally equals to 1 in a normalized sequence for the $k_{t h}$ response, $x_{i}(k)$ is the normalized value, $\Delta \min$ is the minimum value of $\boldsymbol{\Delta}_{o i}$, $\Delta$ max is the maximum value of $\Delta_{o i}$, and $\varsigma$ is the distinguishing coefficient that is set as 0.5 for average distribution.

In recent years, the novel approach that integrates Taguchi method, GRA and fuzzy logic has been successfully applied to optimize multiple QCs of manufacturing processes such as welding engineering $[13,15]$ and materials processes and technology [16-18]. In the fuzzy logic, the membership functions are used to fuzzify the $\delta_{i}(k)$ values of each trial. The $\delta_{1}$ indicates the grey relational coefficient of wetting angle, and $\delta_{2}$ indicates the grey relational coefficient of failure load for each trial of L9 OA in this study. Then, the fuzzify inference engine performs a fuzzy interface on fuzzy rules to generate a fuzzy value. Finally, the defuzzifier transforms the fuzzy value into another value named the grey fuzzy reasoning grade that was used as a multi performance characteristic index (MPCI) to optimize and investigate the MIG arc weld-brazing process [13, 15-18]. In this study, the fuzzy rule base consists of a group of IF and THEN rules with two inputs $\delta_{1}$ and $\delta_{2}$, and one output $z$. It can be summarized using the following equation:

Rule $i$ : If $\delta_{1}$ is $A_{i}$ and $\delta_{2}$ is $B_{i}$ then $z$ is $C_{i}$ else,

Rule $n$ : If $\delta_{1}$ is $A_{n}$ and $\delta_{2}$ is $B_{n}$ then $z$ is $C_{n}$

where $n$ is the total number of fuzzy rules, $i=1,2, \ldots n$, the $\delta_{1}$ and $\delta_{2}$ are input variables calculated from the equation (3). The $A_{i}$ and $B_{i}$ are fuzzy subsets of wetting angle and failure load, respectively, and $C_{i}$ is fuzzy set of MPCI. The fuzzy sets $A_{i}, B_{i}$ and $C_{i}$ defined by the 
corresponding membership functions, i.e., $\mu_{\mathrm{A} i}, \mu_{\mathrm{B} i}$ and $\mu_{\mathrm{C} i}$. The $\delta_{1}$, $\delta_{2}$ and $z$ are the fuzzy values of different fuzzy sets $A_{i}, B_{i}$ and $C_{i}$, respectively. On the basis of the Mamdani implication method of inference reasoning for a set of disjunctive rules, the max-min compositional operation is adopted to calculate fuzzy reasoning. The $\delta_{1}$ and $\delta_{2}$ are the two MIC arc weld-brazing input values, and the membership function of the welding output of fuzzy reasoning is described as the following equation [19-20]:

$$
\begin{aligned}
\mu_{C_{0}}(z)= & \left(\mu A_{1}\left(\delta_{1}\right) \wedge \mu B_{1}\left(\delta_{2}\right) \wedge \mu C_{1}(z)\right) \\
& \vee \ldots . \quad\left(\mu A_{n}\left(\delta_{1}\right) \wedge \mu B_{n}\left(\delta_{2}\right) \wedge \mu C_{n}(z)\right)
\end{aligned}
$$

where $\wedge$ is the minimum operation and $\vee$ is the maximum operation. Finally, the fuzzy values can be combined into one single output value using a defuzzification method. The center of gravity method was employed to transform the fuzzy inference output $\mu_{C_{0}}(z)$ into a nonfuzzy value that adopted as the MPCI.

$$
M P C I=\frac{\sum z \mu_{C_{0}}(z)}{\sum \mu_{C_{0}}(z)}
$$

The MPCI is employed a to optimize and investigate the MIG arc weld-brazing process of Ti/Al lap-joint. The experimental procedure and the proposed approach that for solving multiple QCs problem of the MIG arc weld-brazing process is demonstrated in Fig.2.

\section{Results and discussion}

\subsection{Select major parameters via the screen experiment}

Based on the Table 2, the screen experiment of the MIG arc weld-brazing process was performed to select major parameters. As 
shown in Fig.3, the MIG arc weld-brazing processes under six travel speeds of MIG torch were performed to obtain the performance of Ti/Al lap-joint welds. The grey columns indicate the average tensile strength of specimens, the slash columns indicate the wetting angle of weld beads under different travel speed of MIG torch. When the travel speeds were set at $640 \mathrm{~mm} / \mathrm{min}$, the average tensile strength of specimen that about $160 \mathrm{MPa}$ was the best in the screen experiment. When the travel speeds were set at 640 and $700 \mathrm{~mm} / \mathrm{min}$, the wetting angles of weld bead were 50 and 54 degree, respectively. Based on these results of screen experiment, the levels of MIG torch travel speed were set at 500, 640 and $780 \mathrm{~mm} / \mathrm{min}$, as shown in Table 3. When the wetting angle of Ti/Al lap-joints between 50 and 54, the tensile strength of specimens better than the others, as shown in Fig.3. Therefore, the target value $m$ of wetting angle was set at 52 degree, for the calculation of SNR values using equation (1b) that belongs to the NTB QC in this study.

\subsection{Calculation and analysis of MPCI}

Based on the Table 3 and experimental layout in Table 4, this study carry out the dissimilar materials lap-joint by means of the MIG arc weld-brazing process. The experimental results for the failure load and wetting angle of Ti/Al lap-joint specimens are shown in Tables 5 and 6, respectively. Equation (1a) and (1b) were used to calculate the SNR values of each trial for the failure load and wetting angle of Ti/Al lap-joint specimens. In order to avoid neglecting smaller ranges, the SNR values must be normalized between 0 and 1 [13]. In the calculation of GRA, the $\eta_{i}(k)$ indicates the SNR value of wetting angle or failure load of each trial, the normalized results of each trial are calculated using equation (2). Then, the $\delta_{i}(k)$ as the grey relational coefficients for the wetting angle and failure load corresponding to each trial were calculated 
using the equation (3). The input values $\delta_{1}$ and $\delta_{2}$ for the fuzzy logic system were obtained from wetting angle and failure load of $\mathrm{Ti} / \mathrm{Al}$ lap-joint specimens, respectively. The triangular membership functions were used as the grey relational coefficients of both wetting angle and failure load. There are three fuzzy subsets that including Low, Medium and High grades as shown in Fig. 4a. The triangular membership functions for the output variable MPCI that including five fuzzy subsets, Very poor (VP), P (poor), F (fair), G (good), and VG (Very good) as shown in Fig. 4b. The fuzzy rules for the multiple QCs of Ti/Al lap-joint specimens that employed for the fuzzy logic controllers as shown in Table 8.

\subsection{Acquire optimal parameters and ANOVA via the MPCI}

As shown in Table 7, the input $\delta_{1}$ value of wetting angle is 0.355 that belongs to Low and Medium fuzzy sets and corresponds to fuzzy rules $1-6$. The input $\delta_{2}$ value of failure load is 0.632 that belongs to Medium and High fuzzy sets and corresponds to fuzzy rules 2, 3, 5, 6, 8 and 9. The defuzzified output as the MPCI value is obtained by using the fuzzy rules and membership values that belongs to $\mathrm{P}, \mathrm{F}$, and $\mathrm{G}$. The MPCI value is 0.593 that calculated from the combined darkened area using the MATLAB toolbox, as shown in Fig. 5. The MPCI values for L9 OA of this study are showed in Table 7. Based on the mean of MPCI values for each control factor level, the graph of control factor effect was obtained as shown in Fig. 6. In this proposed approach, the MPCI value of each control factor level that considers with wetting angle and failure load of the Ti/Al lap-joint welds simultaneously. Therefore, the optimal MIG arc weld-brazing parameters of the control factor levels, $\mathrm{A}_{2} \mathrm{~B}_{2} \mathrm{C}_{1}$ were obtained from Fig. 6.

Traditional, the F-ratio through ANOVA only reveals to us the 
significance of a control factor. Taguchi expanded this method and suggested using the percent contribution to construct the contributing percentage of a control factor to the total sum of squares. It can be used to determine the relative capability of a control factor to reduce variation, and the idea is described in the following [14]. The ANOVA results of this study as shown in Table 9, it demonstrated that the welding current (factor B, 76.24\%), and the argon flow rate of MIG torch (factor C, $7.65 \%$ ) are the major MIG arc weld-brazing parameters that affect the multiple QCs of Ti/Al lap-joint specimens. The previous research [10] indicated that the heat input was set appropriately, the Ti plate did not melt due to the high melting point, and the hot liquid $\mathrm{Al}$ alloy spread along the surface of the Ti plate during the MIG arc weld-brazing process. The morphology, composition and thickness of the Ti/Al joint IMCs were found to depend on the welding heat input, and the tensile strength of $\mathrm{Ti} / \mathrm{Al}$ joint was found to be determined by the thickness and morphology of the IMC layers $[3,4]$. The heat input of base metal could be adjusted by welding current regulation. In summary, the MIG welding current is the one of the most crucial control factors during the MIG arc weld-brazing process. In additions, the ANOVA results revealed that the argon flow rate of MIG torch is the other important factor for obtaining multiple QCs of Ti/Al lap-joint.

\subsection{Confirmation and validation of optimal parameters}

The main objective of the confirmation experiment is to verify whether the conclusion acquired by proposed approach is correct or not [14]. This study applied an approach that integrated the Taguchi method, GRA and fuzzy logic to determine the optimal parameters of MIG arc weld-brazing process. The optimal process parameters were obtained as follows: the travel speed of MIG torch at $640 \mathrm{~mm} / \mathrm{min}$, the MIG welding 
current at $18 \mathrm{~A}$, and argon flow rate of MIG torch at $9 \mathrm{~L} / \mathrm{min}$. Fig.7 and Table 10 present the macroscopic morphology and tensile strength testing results of Ti/Al lap-joint that used these MIG arc weld-brazing parameter combinations and other initial welding conditions as shown in Table 2, respectively. The average wetting angle of Ti/Al lap-joint is 50.5 degree as shown in Fig. 7, it near the target value (52 degree) that set by the authors based on the results of screen experiment. As shown in Table 10, the confirmation experiment results of this study demonstrated that the average tensile-strength of Ti/Al lap-joints could reaches $178 \mathrm{MPa}$. The mechanical properties of results are similar to the Ti-6Al-4V/6061AA lap-joint made by a bypass-current MIG weld-brazing that performed by Miao et al. [10]. This reveals that the proposed approach efficiently improves the multiple QCs of the Ti/Al lap-joint simultaneously during the MIG arc weld-brazing process.

Fig. $8 \mathrm{a}, 8 \mathrm{~b}$ and $8 \mathrm{c}$ show the SEM images of fractured surfaces at the fusion zone that marked a red rectangular frame in Fig.7a. The obvious porosities were observed at the fractured surface of fusion zone as shown in Fig. 8a. It implied that porosity in the weld bead of Ti/Al lap-joint facilitated crack propagation through it during the tensile strength testing. Fig. $8 \mathrm{~b}$ shows diameter of the porosities at the fractured surface of fusion zone are about 30 to $100 \mu \mathrm{m}$. Based on the Fig. 6, the MPCI value of $\mathrm{C} 1$ is higher than $\mathrm{C} 2$ or $\mathrm{C} 3$. It demonstrated that the higher flow rate of argon gas from MIG torch nozzle could create a high amount of porosity over the weld bead. During the MIG arc weld-brazing process, the higher shielding gas flow produces turbulence to the weld pool and brings outside air that consequently cause porosity in the weld bead. Fig. 8c shows the dimples at fractured surface that revealed a ductile fracture was occurred in the fusion zone with 4043 filler wire. Fig. 8d shows the SEM images of at the interface between Ti plate and $\mathrm{Al}$ alloys fusion zone that 
marked a red square frame in Fig.7b. It demonstrated that a lamellar IMC layer with a thickness of 0.55 to $0.59 \mu \mathrm{m}$, the brazing performance of confirmation experiment results are similar to the Ti/Al butt-joint that performed by Wan et al. [2] and Li et al. [21]. In summary, this validates that the Ti/Al lap-joint produced by the MIG arc weld-brazing process and proposed approach would obtain a desirable mechanical property and wettability of the Ti/Al lap-joint specimens simultaneously.

\section{Conclusions}

This study applied a proposed approach that integrates Taguchi method, GRA and fuzzy logic to solve multiple QCs optimization problem during the MIG arc weld-brazing process for the Ti/Al lap-joint. The multiple QCs that including wettability and mechanical property of specimens were transformed into a single QC index. The specific conclusions are summarized as follows:

(1) The wettability and mechanical property of the Ti/Al lap-joint specimens were improved simultaneously by using the proposed approach. The experimental procedure of this study can simplify the optimization of the multiple QCs problem, and reduce the cost of weld-brazing process for the Ti/Al dissimilar materials lap-joint.

(2) The average tensile strength of the Ti/Al lap-joint specimens could reaches $178 \mathrm{MPa}$ that produced by the optimal parameters and the double shielding argon gas during the MIG arc weld-brazing process. Experimental results show that the contribution of MIG welding current was $76.24 \%$. It reveals that the MIG welding current is the most significant control factor during the MIG arc weld-brazing process.

(3) Based on the graph of control factor effect, the confirmation experiment results demonstrated that the higher flow rate of argon gas 
could create a high amount of porosity over the weld bead. The higher shielding gas flow produces turbulence to the weld pool and brings outside air that cause porosity in the weld bead.

\section{Declarations}

\section{a. Funding}

This published article was financially supported by the Ministry of Science and Technology (MOST) of Taiwan under the project no. MOST 108-2221-E-017-010.

\section{b. Conflicts of interest/Competing interests}

Not applicable. The authors declare that this published article have no competing interests.

c. Availability of data and material

All data are presented in this published article.

\section{d. Code availability}

Not applicable.

\section{e. Ethics approval}

Not applicable. This published article involves no studies on human or animal subjects.

\section{f. Consent to participate}

Not applicable. This published article involves no studies on human subjects.

\section{g. Consent for publication}

Not applicable. This published article involves no studies on human subjects.

\section{h. Authors' contributions}

Hsuan-Liang Lin devised the MOST project, the main conceptual ideas, proof outline and performed the grey relational analysis and fuzzy logic calculations. You-Jiun Wang performed all of the 
experiments, the Taguchi method calculations for the proposed approach and verified the experimental results by using OM and SEM. Hsuan-Liang Lin proposed the integrated approach in discussions with You-Jiun Wang. All authors discussed the results and contributed to the final manuscript.

\section{References}

[1] Baqer YM, Ramesh S, Yusof F et al (2018) Challenges and advances in laser welding of dissimilar light alloys: $\mathrm{Al} / \mathrm{Mg}, \mathrm{Al} / \mathrm{Ti}$, and $\mathrm{Mg} / \mathrm{Ti}$ alloys. The International Journal of Advanced Manufacturing Technology 95: 4353-4369

[2] Wan L, Lv S, Huang Y et al (2015) Effect of hot dip aluminizing on interfacial microstructure and mechanical properties of $\mathrm{Ti} / \mathrm{Al}$ joint by TIG arc welding brazing. Science and Technology of Welding and Joining 20 (2): 164-171

[3] Chen WB (2016) Microstructure and mechanical properties of tungsten inert gas welded-brazed Al/Ti joints. Science and Technology of Welding and Joining 21 (7): 547-554

[4] Zhang Y, Huang J, Ye Z et al (2018) Influence of welding parameters on the IMCs and the mechanical properties of Ti/Al butt joints welded by MIG/TIG double-sided arc welding-brazing. Journal of Alloys and Compounds 747: 764-771

[5] Li P, Lei Z, Zhang X et al (2020) Effects of laser power on the interfacial intermetallic compounds and mechanical properties of dual-spot laser welded-brazed Ti/Al butt joint. Optics and Laser Technology 124: 105987

[6] Mathieu A, Shabadi R, Deschamps A et al (2007) Dissimilar material joining laser (aluminum to steel using zinc-based filler wire). Optics \& Laser Technology 39: 652-661

[7] Chen Y, Chen S, Li L (2009) Effects of heat input on microstructure and mechanical property of $\mathrm{Al} / \mathrm{Ti}$ joints by rectangular spot laser welding-brazing method. The International Journal of Advanced Manufacturing Technology 44: 265-272

[8] Li Y, Zhang Y, Luo Z (2015) Microstructure and mechanical properties of Al/Ti joints welded by resistance spot welding. Science and Technology of Welding and Joining 20 (5): 385-394

[9] Nandagopal K, Kailasanathan C (2016) Analysis of mechanical properties and optimization of gas tungsten arc welding (GTAW) parameters on dissimilar metal titanium (6Al-4V) and aluminum 7075 by Taguchi and ANOVA techniques. Journal of Alloys and Compounds 682: 503-516

[10] Miao Y, Ma Z, Yang X et al (2018) Experimental study on microstructure and mechanical properties of AA6061/Ti-6Al-4V joints made by bypass-current MIG welding-brazing. Journal of Materials Processing Technology 260: 104-111

[11] Singh J, Arora KS, Shukla DK (2020) Lap weld-brazing of aluminum to steel using novel cold metal transfer process. Journal of Materials Processing Technology 283: 116728

[12] Lin HL, Yan JC (2014) Optimization of weld bead geometry in the activated GMA welding process via a grey-based Taguchi method. Journal of Mechanical 
Science and Technology 28(8): 3249-3254

[13] Lin HL (2017) Applying gray fuzzy logic to decide the weight ratio of activating flux during activated MIG aluminum alloy butt-joint welding. The International Journal of Advanced Manufacturing Technology 92: 471-479

[14] Su Chao-Ton (2013) Quality engineering: off-line methods and applications. CRC Press (Taylor \& Francis Group), London

[15] Sahu PK, Kumari K, Pal S et al (2016) Hybrid fuzzy-grey-Taguchi based multi weld quality optimization of $\mathrm{Al} / \mathrm{Cu}$ dissimilar friction stir welded joints. Advances in Manufacturing 4: 237-247

[16] Yang YS, Huang W (2012) A grey-fuzzy Taguchi approach for optimizing multi-objective properties of zirconium-containing diamond-like carbon coatings. Expert Systems with Applications 39: 743-750

[17] Lin CL, Lin JL, Ko TC (2002) Optimisation of the EDM process based on the orthogonal array with fuzzy logic and grey relational analysis method. The International Journal of Advanced Manufacturing Technology 19: 271-277

[18] Das S, Das S, Gautam SS et al (2020) Optimization of wear coefficient and coefficient of friction of borosilicate glass ceramic using Taguchi coupled grey fuzzy logic technique. Materials Today: Proceedings 27: 1579-1589

[19] Pandey AK, Dubey AK (2012) Taguchi based fuzzy logic optimization of multiple quality characteristics in laser cutting of Duralumin sheet. Optics and Lasers in Engineering 50: 328-335

[20] Kuo CC, Lin BT, Wang WT (2019) Optimization of microridge punch design for deep drawing process by using the fuzzy Taguchi method. The International Journal of Advanced Manufacturing Technology 103: 177-186

[21] Li P, Lei Z, Zhang X et al (2020) Influence of Si content on interfacial reactions and mechanical properties of dual-spot laser welded-brazed Ti/Al joints. Journal of Manufacturing Processes 56: 950-966

\section{Figure captions}

Fig. 1 Schematic of the MIG arc weld-brazing and sampling specimens

Fig. 2 Experimental procedure and the proposed approach

Fig. 3 Results of screen experiment for travel speed of MIG torch

Fig. 4 Membership functions for input and multiple QCs output

Fig. 5 Fuzzy logic rules viewer for the trial no.1

Fig. 6 Graph of control factor effect for the MPCI

Fig. 7 Macroscopic morphology of the Ti/Al lap-joint cross-sections

Fig. 8 Micrograph of fractured surface and Ti/Al lap-joint cross-section 
Table 1 Chemical content of Al alloy, 4043 filler wire and Ti alloy

\begin{tabular}{ccccccccccc}
\hline Materials & $\mathrm{Si}$ & $\mathrm{Fe}$ & $\mathrm{Cu}$ & $\mathrm{Mn}$ & $\mathrm{Mg}$ & $\mathrm{Cr}$ & $\mathrm{Zn}$ & $\mathrm{Ti}$ & $\mathrm{V}$ & $\mathrm{Al}$ \\
\hline $6061 \mathrm{Al}$ & 0.6 & 0.7 & 0.25 & 0.15 & 1.1 & 0.2 & 0.25 & 0.15 & - & Bal. \\
Filler wire & 5.0 & 0.8 & 0.3 & 0.05 & 0.05 & - & 0.1 & 0.2 & - & Bal. \\
Ti-6Al-4V & - & 0.3 & - & - & - & - & - & Bal. & $3.5-4.5$ & $5.5-6.75$ \\
\hline
\end{tabular}

Table 2 Process parameters used in screen experiment

MIG arc weld-brazing parameters Values

MIG welding current, A

MIG welding voltage, $\mathrm{V}$

Electrode offset distance from Al plate side, $\mathrm{mm}$

Argon flow rate of the MIG torch, L/min

Argon flow rate on the surface of Ti plate, L/min

Travel speed of MIG torch, $\mathrm{mm} / \mathrm{min}$

Table 3 MIG arc weld-brazing parameters and their levels

\begin{tabular}{llccc}
\hline \multicolumn{1}{c}{ Process parameters } & Level 1 & Level 2 & Level 3 \\
\hline A & Travel speed of MIG torch, mm/min & 500 & 640 & 780 \\
B & MIG welding current, A & 15 & 18 & 21 \\
C & Argon flow rate of MIG torch, L/min & 9 & 12 & 15 \\
\hline
\end{tabular}


Table 4 Experimental layout using the Taguchi method L9 OA

\begin{tabular}{|c|c|c|c|c|c|c|c|}
\hline \multirow{4}{*}{$\begin{array}{c}\text { Trial } \\
\text { no. }\end{array}$} & \multicolumn{3}{|c|}{ Control factors } & \multicolumn{4}{|c|}{ Noise factor } \\
\hline & \multirow{3}{*}{ A } & \multirow{3}{*}{ B } & \multirow{3}{*}{$\mathrm{C}$} & \multicolumn{2}{|c|}{ Specimen 1} & \multicolumn{2}{|c|}{ Specimen 2} \\
\hline & & & & N 1 & $\mathrm{~N} 2$ & N1 & $\mathrm{N} 2$ \\
\hline & & & & $\mathrm{y}_{1}$ & $\mathrm{y}_{2}$ & $\mathrm{y}_{3}$ & $\mathrm{y}_{4}$ \\
\hline 1 & 1 & 1 & 1 & \multirow{9}{*}{\multicolumn{4}{|c|}{ Failure load of the specimens }} \\
\hline 2 & 1 & 2 & 2 & & & & \\
\hline 3 & 1 & 3 & 3 & & & & \\
\hline 4 & 2 & 1 & 3 & & & & \\
\hline 5 & 2 & 2 & 1 & & & & \\
\hline 6 & 2 & 3 & 2 & & & & \\
\hline 7 & 3 & 1 & 2 & & & & \\
\hline 8 & 3 & 2 & 3 & & & & \\
\hline 9 & 3 & 3 & 1 & & & & \\
\hline
\end{tabular}

Table 5 Experimental results of the failure load and SNR calculations

\begin{tabular}{|c|c|c|c|c|c|}
\hline \multirow{2}{*}{ Trial no. } & \multicolumn{4}{|c|}{ Failure load of the specimens, N } & \multirow{2}{*}{$\begin{array}{c}\text { SNR } \\
(\mathrm{dB})\end{array}$} \\
\cline { 2 - 5 } & $\mathrm{y}_{1}$ & $\mathrm{y} 2$ & $\mathrm{y}_{3}$ & $\mathrm{y}_{4}$ & \\
\hline 1 & 2563.84 & 2033.97 & 2390.03 & 2369.59 & 67.287 \\
\hline 2 & 2932.49 & 3358.09 & 2955.02 & 2937.01 & 69.632 \\
\hline 3 & 2697.20 & 2740.56 & 2870.37 & 2830.84 & 68.888 \\
\hline 4 & 1880.32 & 870.34 & 1466.66 & 1666.46 & 62.168 \\
\hline 5 & 3061.80 & 2675.16 & 3171.48 & 2967.43 & 69.399 \\
\hline 6 & 3044.29 & 2520.63 & 3070.75 & 2796.87 & 69.038 \\
\hline 7 & 1075.24 & 937.43 & 1659.74 & 1540.14 & 61.568 \\
\hline 8 & 2638.61 & 2145.35 & 2557.83 & 2546.11 & 67.773 \\
\hline 9 & 2483.19 & 2957.45 & 3167.62 & 3464.12 & 69.398 \\
\hline
\end{tabular}


Table 6 Experimental results of wetting angle and SNR calculations

\begin{tabular}{|c|c|c|c|c|c|}
\hline \multirow{2}{*}{ Trial no. } & \multicolumn{2}{|c|}{ Wetting angle, Degrees } & \multirow{2}{*}{ Average } & \multirow{2}{*}{$\begin{array}{l}\text { Standard } \\
\text { deviation }\end{array}$} & \multirow{2}{*}{$\begin{array}{l}\text { SNR } \\
(\mathrm{dB})\end{array}$} \\
\hline & Specimen 1 & Specimen 2 & & & \\
\hline 1 & 74 & 69 & 71.50 & 3.54 & 26.117 \\
\hline 2 & 76 & 65 & 70.50 & 7.78 & 19.146 \\
\hline 3 & 70 & 59 & 64.50 & 7.78 & 18.374 \\
\hline 4 & 65 & 64 & 64.50 & 0.71 & 39.201 \\
\hline 5 & 54 & 59 & 56.50 & 3.54 & 24.072 \\
\hline 6 & 40 & 53 & 46.50 & 9.19 & 14.080 \\
\hline 7 & 52 & 26 & 39.00 & 18.38 & 6.532 \\
\hline 8 & 57 & 47 & 52.00 & 7.07 & 17.330 \\
\hline 9 & 40 & 42 & 41.00 & 1.41 & 29.245 \\
\hline
\end{tabular}

Table 7 Grey relational analysis for the MPCI of each trial

\begin{tabular}{|c|c|c|c|c|c|}
\hline \multirow{2}{*}{$\begin{array}{c}\text { Trial } \\
\text { no. }\end{array}$} & \multicolumn{2}{|c|}{ Normalized values } & \multicolumn{2}{c|}{ Grey relational coefficients } & \multirow{2}{*}{ MPCI } \\
\cline { 2 - 5 } & Wetting angle & Failure load & Wetting angle & Failure load & \\
\hline 1 & 0.093 & 0.709 & 0.355 & 0.632 & 0.593 \\
\hline 2 & 0.084 & 1.000 & 0.353 & 1.000 & 0.700 \\
\hline 3 & 0.310 & 0.908 & 0.420 & 0.844 & 0.727 \\
\hline 4 & 0.428 & 0.074 & 0.467 & 0.351 & 0.449 \\
\hline 5 & 1.000 & 0.971 & 1.000 & 0.945 & 0.905 \\
\hline 6 & 0.542 & 0.926 & 0.522 & 0.872 & 0.802 \\
\hline 7 & 0.000 & 0.000 & 0.333 & 0.333 & 0.357 \\
\hline 8 & 0.846 & 0.769 & 0.764 & 0.684 & 0.860 \\
\hline 9 & 0.517 & 0.971 & 0.509 & 0.945 & 0.801 \\
\hline
\end{tabular}


Table 8 Fuzzy rules for multiple QCs of the Ti/Al lap-joint specimens

\begin{tabular}{ccccc}
\hline \multirow{2}{*}{$\begin{array}{c}\text { Multi performance characteristic index, } \\
\text { MPCI }\end{array}$} & \multicolumn{3}{c}{$\begin{array}{c}\text { Grey relational coefficient of } \\
\text { failure load, }\end{array}$} \\
\cline { 3 - 5 } & & Low & Medium & High \\
\hline \multirow{2}{*}{$\begin{array}{c}\text { Grey relational coefficient of } \\
\text { wetting angle, } \delta_{1}\end{array}$} & Very poor & Poor & Fair \\
& Medium & Poor & Fair & Good \\
& High & Fair & Good & Very good \\
\hline
\end{tabular}

Table 9 Results of the ANOVA for the MPCI values

\begin{tabular}{lcccccc}
\hline Factor & $\begin{array}{c}\text { Degrees of } \\
\text { freedom }\end{array}$ & $\begin{array}{c}\text { Sum of } \\
\text { square }\end{array}$ & $\begin{array}{c}\text { Mean } \\
\text { square }\end{array}$ & F0 & $\begin{array}{c}\text { Pure sum } \\
\text { of square }\end{array}$ & $\begin{array}{c}\text { Percent } \\
\text { contribution }\end{array}$ \\
\hline A & 2 & $0.004^{*}$ & & & & \\
B & 2 & 0.225 & 0.112 & 19.93 & 0.21 & $76.24 \%$ \\
C & 2 & 0.033 & 0.016 & 2.90 & 0.02 & $7.65 \%$ \\
$\begin{array}{l}\text { Error } \\
\text { (pooled error) }\end{array}$ & $(4)$ & $(0.023)$ & $(0.006)$ & & 0.05 & $16.11 \%$ \\
Total & 8 & 0.28 & & & 0.27 & $100.00 \%$ \\
\hline
\end{tabular}

* Indicates sum of square that were combined to estimate the pooled error.

Table 10 Results of the confirmation experiment

\begin{tabular}{ccrrrc}
\hline Specimen & Position & $\begin{array}{c}\text { Failure load, } \\
\text { N }\end{array}$ & $\begin{array}{c}\text { Tensile strength, } \\
\text { MPa }\end{array}$ & Fracture location & $\begin{array}{c}\text { Wetting angle, } \\
\text { Degrees }\end{array}$ \\
\hline \multirow{2}{*}{1} & N1 & 3399 & 174.1 & Fusion zone & 52 \\
& N2 & 2857 & 151.1 & Fusion zone & \\
2 & N1 & 3565 & 198.1 & Fusion zone & 49 \\
\hline
\end{tabular}


Figures
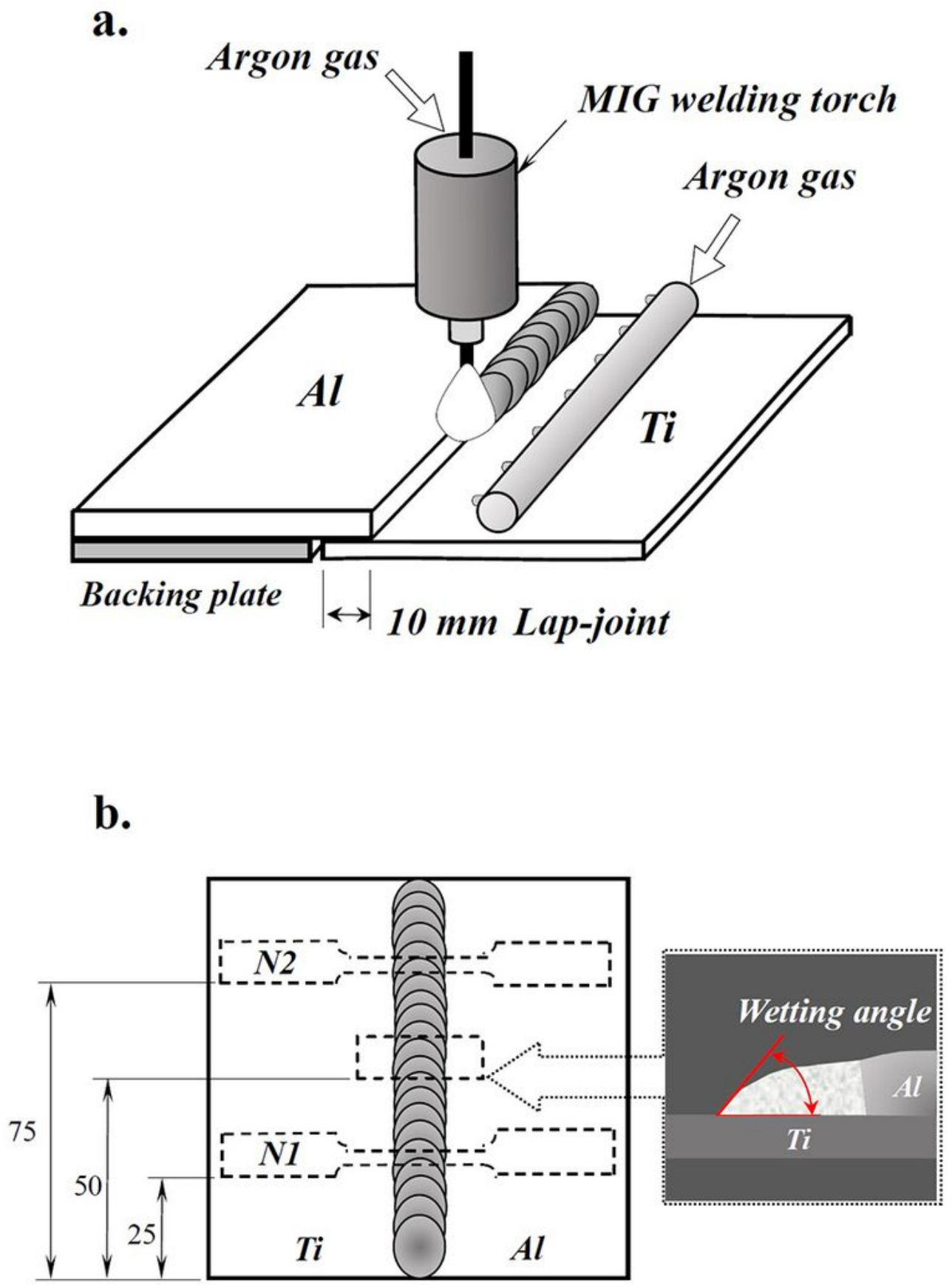

Figure 1

Schematic of the MIG arc weld-brazing and sampling specimens 


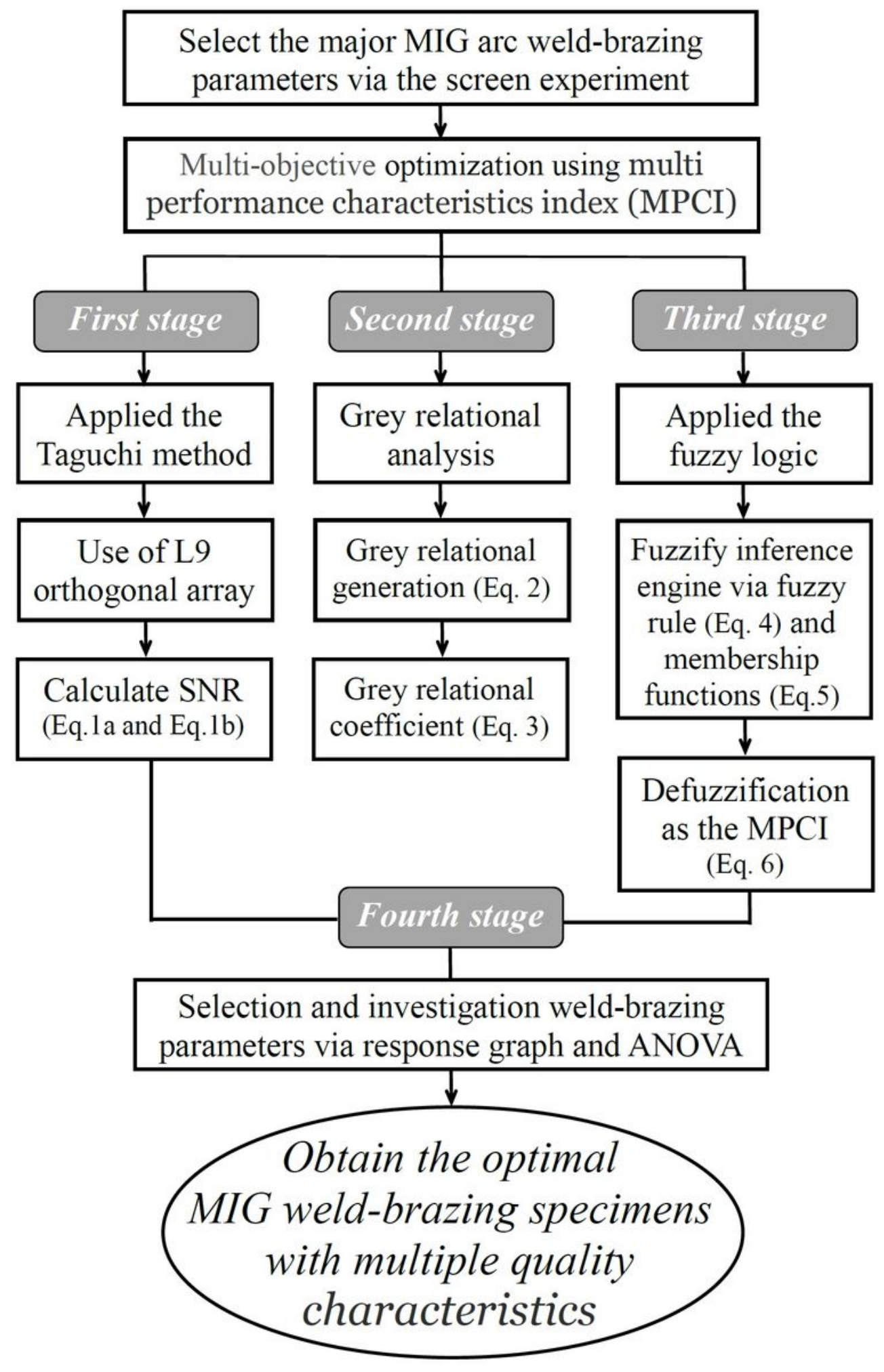

Figure 2

Experimental procedure and the proposed approach 


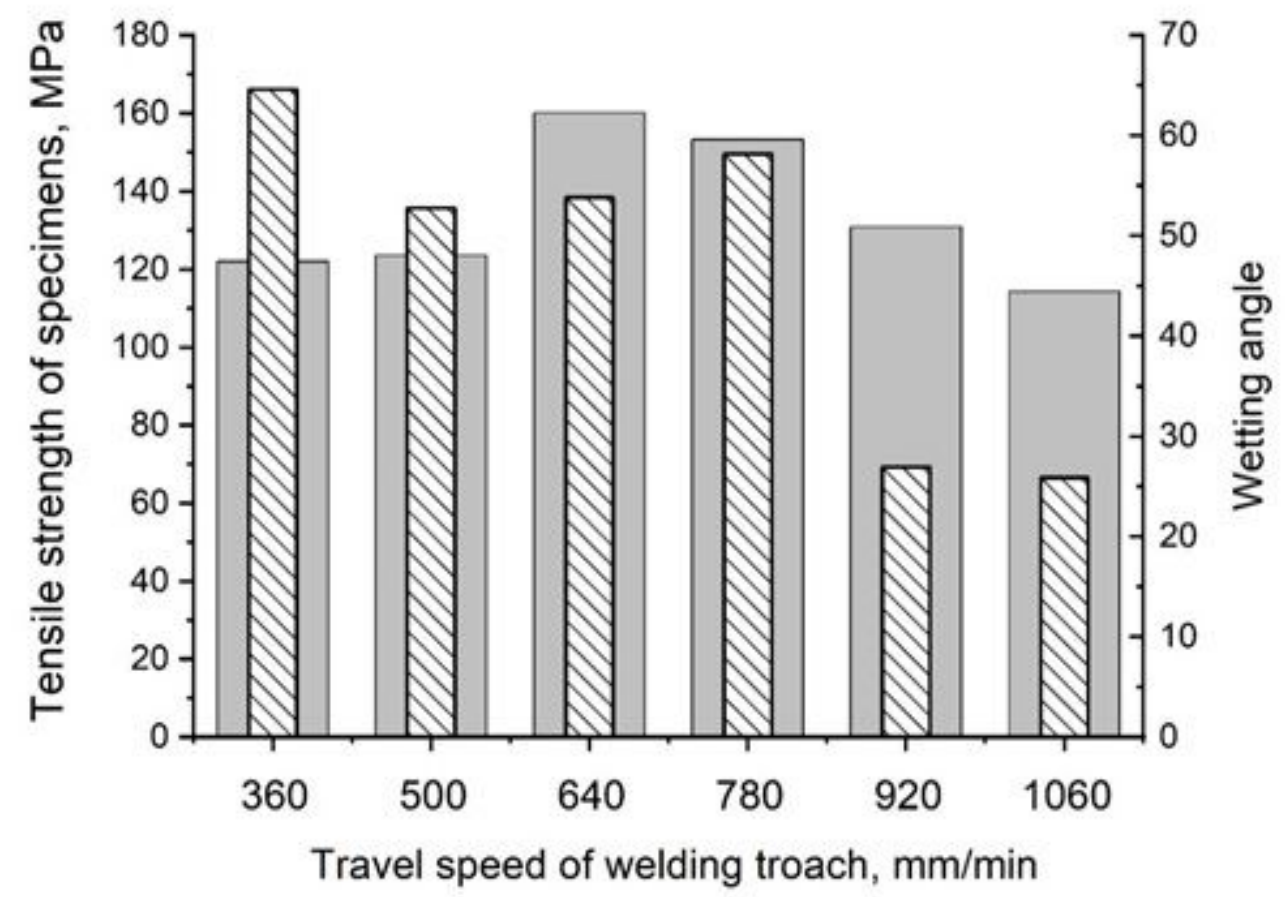

Figure 3

Results of screen experiment for travel speed of MIG torch 
Wetting angle $=0.355$ Failure load $=0.632 \quad \mathrm{MPCl}=0.593$

1

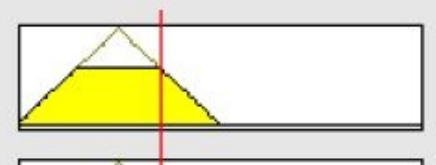

2

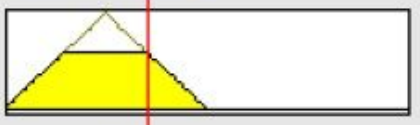

3

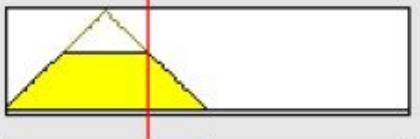

4

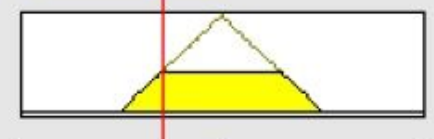

5

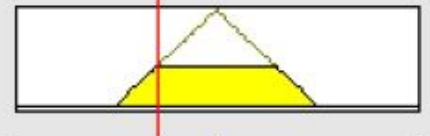

6

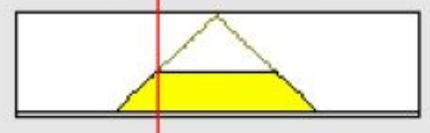

7

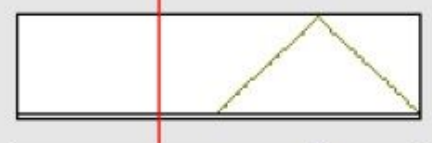

8

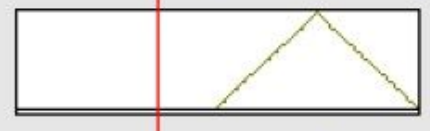

9

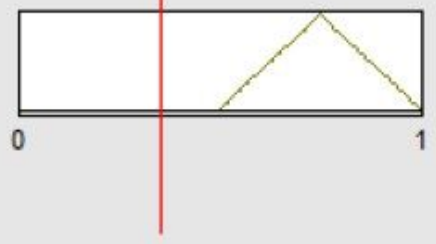

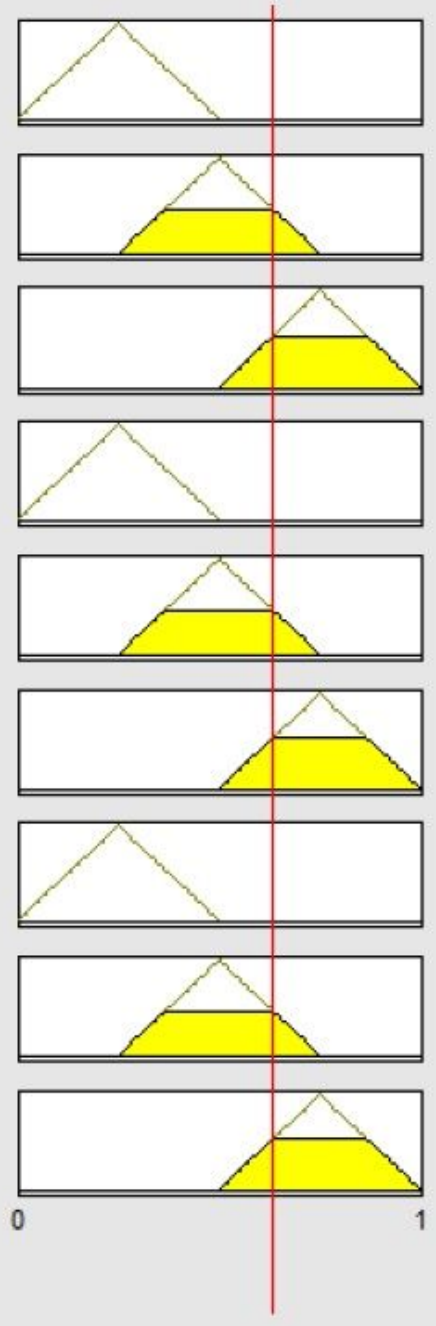
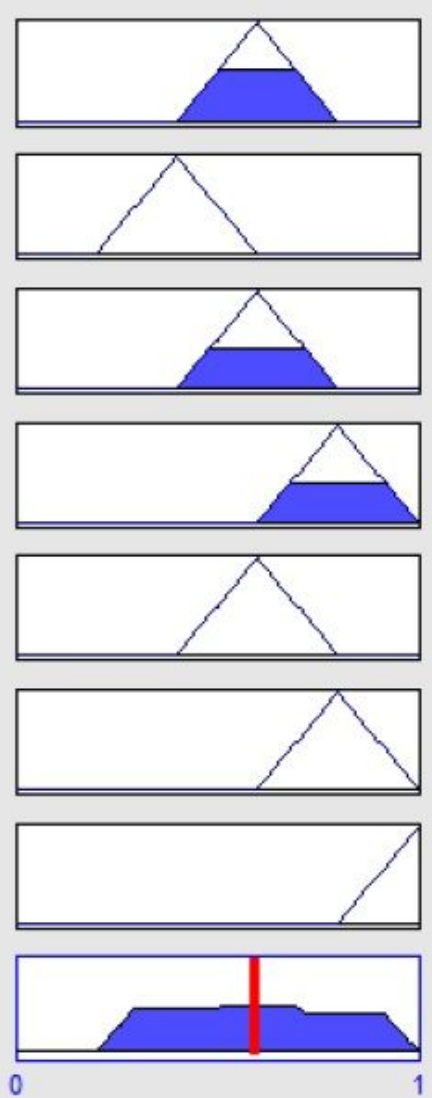

Figure 5

Fuzzy logic rules viewer for the trial no. 1 


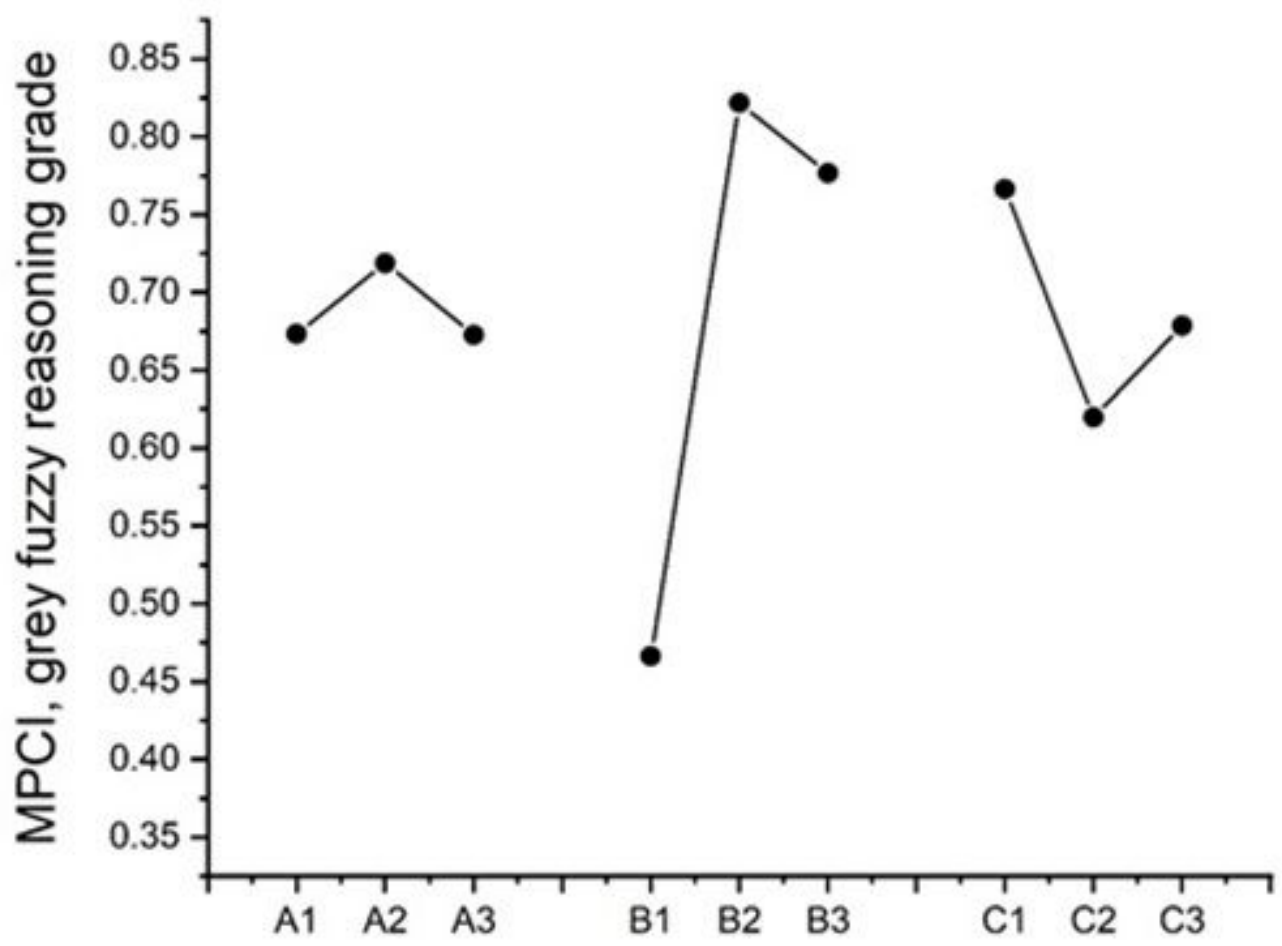

MIG weld-brazing parameter levels

Figure 6

Graph of control factor effect for the MPCl

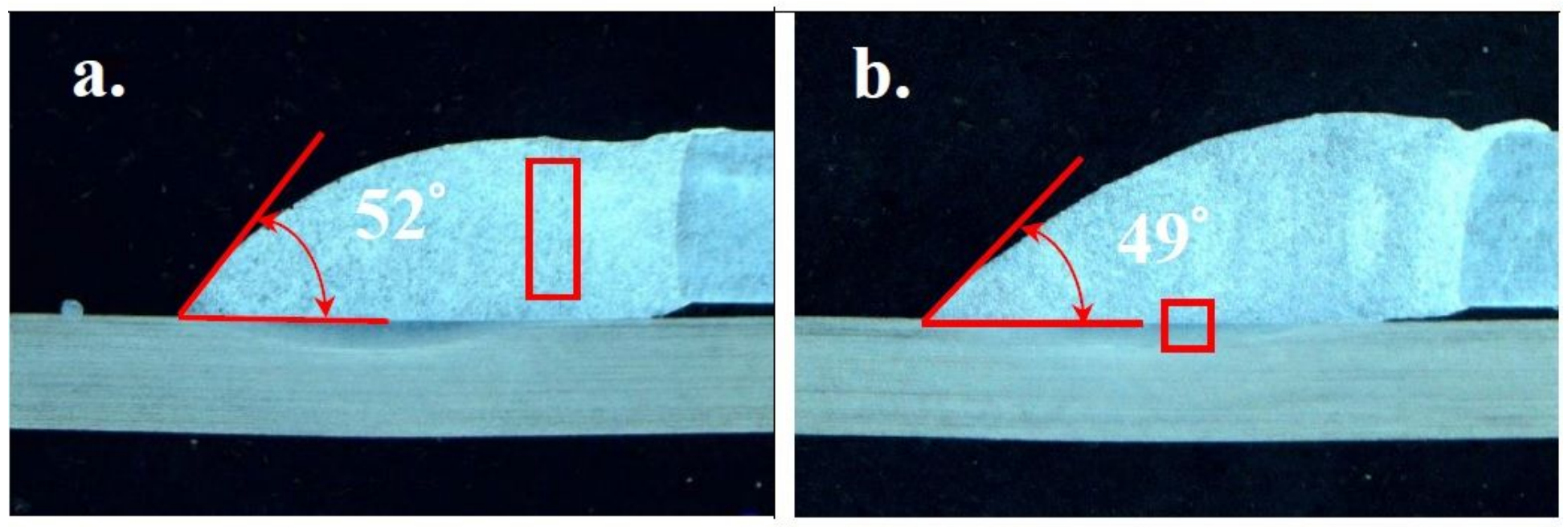

Figure 7

Macroscopic morphology of the Ti/Al lap-joint cross-sections 


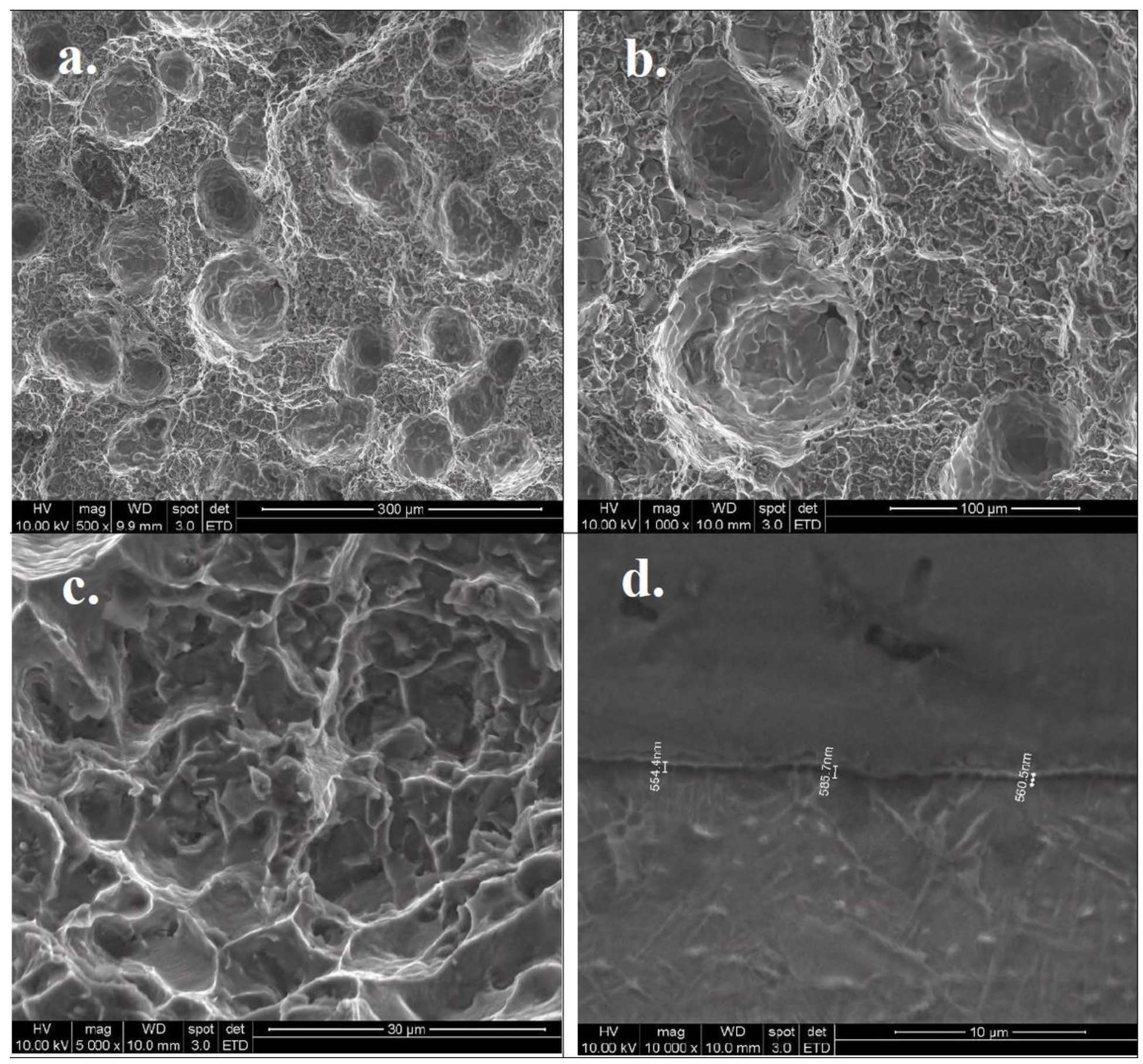

Figure 8

Micrograph of fractured surface and Ti/Al lap-joint cross-section 